\title{
Evaluación de la dinámica de conservación del producto final de un alimento obtenido por fermentación en estado sólido de la papa (Fes-papa)
}

\author{
Final product conservation dynamic evaluation of a \\ food obtained by the potato solid state fermentation \\ (Fes-potato)
}

Fecha de recepción: 1 de agosto de 2014

Fecha de aceptación: 1 de noviembre de 2014
Luis Miguel Borras-Sandoval ${ }^{1}$, Arabel Elías Iglesias², Gabriel Fernando Saavedra-Montañez ${ }^{3}$

\section{Resumen}

Se expone el efecto de la fermentación en estado sólido sobre un alimento preparado a base del tubérculo de la papa (Solanum tuberosum), y su posible utilización en la alimentación animal. La papa fresca y picada se mezcló con un material fibroso secante (harina de alfalfa), melaza, urea, un preparado microbiano, premezcla mineral, carbonato de calcio y sulfato de sodio, y se dejó fermentar, acorde con el tiempo y la temperatura previamente establecidos $\left(48 \mathrm{~h}\right.$ y $\left.20^{\circ} \mathrm{C}\right)$, en bolsas plásticas de $50 \mathrm{~kg}$. El producto Fes-papa se muestreó el día uno de elaboración y a los treinta y noventa días. El producto Fes-papa presentó modificaciones significativas en los indicadores fermentativos evaluados. El pH descendió constantemente desde el inicio (6.3) hasta terminar la evaluación ( $\mathrm{pH}$ 4.86); algo similar ocurrió con la materia seca (MSI) y el componente fibroso (FDN-FDA), los cuales descendieron con el tiempo de fermentación, mejorando sensiblemente la digestibilidad del producto. La Fes-papa es un proceso biotecnológico sencillo para aprovechar los tubérculos de los residuos de cosecha y generar un alimento energético-proteico que, acorde con los indicadores fermentativos y contenido en MS, pudiera ser empleado en la alimentación animal; además, contrarrestaría la contaminación ambiental.

Palabras clave: Fermentación en estado sólido, Incubación, Contaminación ambiental, Papa, Biotecnología, Preparado microbiano.

Ph.D.(c). Universidad Pedagógica y Tecnológica de Colombia (Tunja, Colombia). luis.borras@uptc.edu.co.

Ph.D. Instituto de Ciencia Animal - ICA (Mayabeque, Cuba). aelias@ica.co.cu

Profesional Independiente. 


\begin{abstract}
The present work shows the solid state fermentation effect on a type of food prepared on potato tuber (Solanum tuberosum) basis and their possible use in animal feed. Some chopped fresh potato was mixed with a drying fibrous material (alfalfa meal), molasses, urea, a microbial preparation, mineral premix, calcium carbonate and sodium sulfate and then fermented according to the time and temperature previously established ( $48 \mathrm{~h}$ and $20^{\circ} \mathrm{C}$ ), in plastic bags of $50 \mathrm{~kg}$ capacity. The Fes-potato product was sampled the day one and then at thirty to ninety days respectively. The Fes-potato product showed significant changes in the fermentation indicators evaluated. The $\mathrm{pH}$ fell steadily from baseline (6.3) to complete the evaluation $(\mathrm{pH} \mathrm{4.86)}$ at 48 hours, regardless of the incubation temperature. Something similar happened with the dry matter (MSI) and the fibrous component (FDN-FDA), which decreased with the fermentation time, sensible improving the product digestion. The Fes-potato is a simple process to take advantage of the biotechnology tubers crop residues, and to generate an energy-protein food, consistent with the content in MS fermentative indicators that could be used in animal feed; plus it should help to counteract environmental pollution.
\end{abstract}

Keywords: Solid State Fermentation, Incubation, Environmental Pollution, Potato, Biotechnology, Prepared microbial. 


\section{Introducción}

América Latina produce anualmente cerca de 8 millones de toneladas de papas; la producción y el rendimiento varían considerablemente entre países; dentro de la Zona Andina, Colombia tiene la más alta rata de crecimiento de la producción y rendimiento. La producción de papa ha aumentado cerca del $300 \%$ desde los comienzos de la década de los sesenta del siglo pasado, como respuesta a la fuerte demanda del producto para consumo en fresco y procesada; tal aumento, ha sido facilitado, entre otras cosas, por la disponibilidad de un buen sistema de manejo de plagas y enfermedades (1).

La papa tiene un potencial muy grande para la alimentación animal, especialmente de rumiantes, pues al tener gran cantidad de almidón se convierte en una fuente importante de carbohidratos $\left(\mathrm{CHO}^{\prime} \mathrm{s}\right)$, que son el corazón de toda dieta exitosa; estos conforman el $70 \%$ o más de la materia seca (MS) consumida y aportan la mayor parte de la energía, incluyendo el "efecto fibra". Los carbohidratos no fibrosos (CNF) aportan, aproximadamente, la mitad del total de los $\mathrm{CHO}^{\prime} \mathrm{s}$, mientras el remanente proviene de la conocida fibra en detergente neutro (FDN) (2).

Áreas del trópico, entre ellas Colombia, con una masa ganadera bovina, porcina y aviar, y con presencia de sistemas especializados para ellas, pueden convertirse en potencias para la producción de alimentos proteínicos de origen animal (leche, carne, huevos), de alto valor biológico para el consumo humano; sin embargo, para mantener una producción constante y eficiente de alimentos es necesario el suministro de dietas bien formuladas, con alta proporción de cereales y concentrados de energía y proteína suficientes.

Por otro lado, se espera que la producción de biocombustibles se incremente casi $70 \%$ y que el biodiesel aumente aún más rápido. Para el 2022 se prevé que la producción de biocombustibles consumirá el $28 \%$ de la producción mundial de caña de azúcar, el $15 \%$ de los aceites vegetales y $12 \%$ de los cereales secundarios (3).
Todo lo anterior demuestra que es urgente encontrar ingredientes alternativos que nutricionalmente puedan sustituir al maíz y la soya en la formulación de concentrados para la alimentación animal. En este sentido, en Colombia la papa puede contribuir sustancial y sosteniblemente a obtener concentrados energético-proteicos a través de sistemas biotecnológicos como FES de la papa, con el apoyo de la tecnología desarrollada al respecto en el Instituto de Ciencia Animal de Cuba-ICA- $(4,5)$.

\section{Materiales y métodos}

Localización geográfica del área de estudio: la investigación se desarrolló en la finca "San José", ubicada en la vereda Poravita, del municipio de Oicatá, departamento de Boyacá, Colombia; cuenta con un área total de $59 \mathrm{~km}^{2}$, se encuentra entre los pisos térmicos frío y páramo, cuya temperatura oscila entre 10 y $14^{\circ} \mathrm{C}$, y la precipitación se presenta entre 600 y $1.000 \mathrm{~mm}$. La cabecera municipal de este municipio se localiza a los $5^{\circ} 33^{\prime} 40^{\prime \prime}$ de latitud norte y a $0^{\circ} 47^{\prime} 00^{\prime \prime}$ de latitud norte con relación al meridiano de Santafé de Bogotá, y a los $73^{\circ} 18^{\prime} 00^{\prime \prime}$ longitud al oeste de Greenwich. Su altura barométrica es de 2.815 m.s.n.m. (6).

Procedimiento experimental: en la preparación del producto Fes-papa se empleó tubérculo completo de papa obtenida comercialmente, el cual fue limpiado y picado finamente, y otros ingredientes y fuentes energéticas, según método descrito preestablecido (4); la composición total del producto fue la siguiente: $68,5 \%$ de papa, $25 \%$ de material fibroso secante (harina de alfalfa), $2 \%$ de melaza, $1 \%$ de urea, $2 \%$ de preparado microbiano, $0,5 \%$ de premezcla mineral, 0,5 de carbonato de calcio y $0,5 \%$ de sulfato de sodio. Estos ingredientes se mezclaron hasta obtener una pasta homogénea, que denominamos producto Fes-papa; parte de este se dispuso para realizar los análisis de indicadores fermentativos del producto a la hora 0 y a temperatura ambiente, y el producto restante se distribuyó en bolsas plásticas selladas no herméticamente de $50 \mathrm{~kg}$ de capacidad, para ser incubado a $20^{\circ} \mathrm{C}$ y en periodos de 30 y 90 días, respectivamente; cada bolsa representó una unidad experimental, con tres repeticiones respectivamente. 
El producto se mantuvo a $20^{\circ} \mathrm{C}$, en un invernadero plástico adecuado para tal fin con sistema de cortinas para regulación de temperatura; pasados $30 \mathrm{y}$ 90 días de incubación se procedió a tomar parte de cada una de las muestras del producto para análisis químico.

Análisis químico: se tomaron $5 \mathrm{~g}$ de muestra, se colocaron en un Erlenmeyer de $100 \mathrm{~mL}$ y se les adicionó $45 \mathrm{~mL}$ de agua destilada estéril (fresca). La preparación se agitó durante 30 minutos en un agitador eléctrico marca Adams ${ }^{\circledR}$ y posteriormente se obtuvo el filtrado mediante gasas estériles para medición del $\mathrm{pH}$ en un potenciómetro automático marca Okaton ${ }^{\circledR}$ (4); muestreo realizado con una periodicidad de 8 días entre cada uno. Se determinó el porcentaje de nitrógeno amoniacal (NH3) (7), Materia seca (MS), Cenizas (CZ), Proteína Cruda (PC) (8), Proteína de filtrado (PV) (9), fibra neu- tra detergente (FND) y fibra ácida detergente (FAD) (10).

Elaboración del inóculo: la elaboración del preparado microbiano parte de la utilización de un cultivo comercial liofilizado (Liofast Y452B, SACCO ${ }^{\circledR}$ ) como fuente de bacterias acidolácticas, preparadas con una mezcla de leche entera de vaca y fuentes energéticas, proteicas y minerales; el preparado se calentó a $45^{\circ} \mathrm{C}$ y se inoculó con el cultivo, durante un tiempo de 6-8 h, llevando a un volumen final con agua e incubando a $48 \mathrm{~h}$ hasta alcanzar un $\mathrm{pH}$ de 4.5, con agitación 3 veces al día durante 20 minutos.

Análisis microbiológico del producto final: el producto final se muestreó a los 30 días de elaboración y se le realizó un control microbiológico, con el objeto de garantizar su inocuidad, como se muestra en la Tabla I.

Tabla I. Análisis Microbiológico Fes-papa

\begin{tabular}{|c|c|}
\hline Análisis microbiológico & Método \\
\hline Aerobios mesófilos (UFC/g) & AOAC 966.23.C:2001 \\
\hline Coliformestotales (NMP) & ICMSF NMP:2000 \\
\hline Coliformesfecales (NMP) & ICMSF NMP:2000 \\
\hline Esporas Clostridum Sulfito Reductor (UFC/g) & ISO 15213:2003 \\
\hline Mohos y levaduras (UFC/g) & ISO 7954:1987 \\
\hline Salmonella & AS 5013.10:2009 \\
\hline Bacterias acidolácticas & NTC 5034/2002 \\
\hline
\end{tabular}

Diseño experimental: se utilizó un diseño completamente al azar para evaluar un tratamiento y tres repeticiones en el tiempo.

Análisis estadístico: los resultados de calidad composicional, al igual que los parámetros de fermentación, se obtuvieron mediante un análisis de varianza (Anova); también se utilizó la prueba de comparación de promedios de Tukey $(5 \%)$, mediante el uso del software SAS v. 9.2 (Cary, N.C.). Los resultados obtenidos a partir del crecimiento microbiológico se sometieron a una estadística descriptiva del conteo total de unidades formadoras de colonias.

\section{Resultados y discusión}

Como se observa en la Fig.1, el alimento se comporta de forma similar a las pruebas previas de laboratorio, es decir, se da inicialmente un descenso progresivo en el tiempo del $\mathrm{pH}$, a partir de un 6,7 inicial, seguido de una estabilización; en el siguiente muestreo, realizado a los 8 días, el $\mathrm{pH}$ ya sea había estabilizado en 5.18, pH que no presentó cambios significativos, manteniéndose en promedio sobre un $\mathrm{pH}$ de 5.0 en casi todo el tiempo de muestreo; se reporta que el $\mathrm{pH}$ se debe mantener entre 3.5 y 6 para un adecuado crecimiento de microorganismos en procesos FES $(11,4)$. 


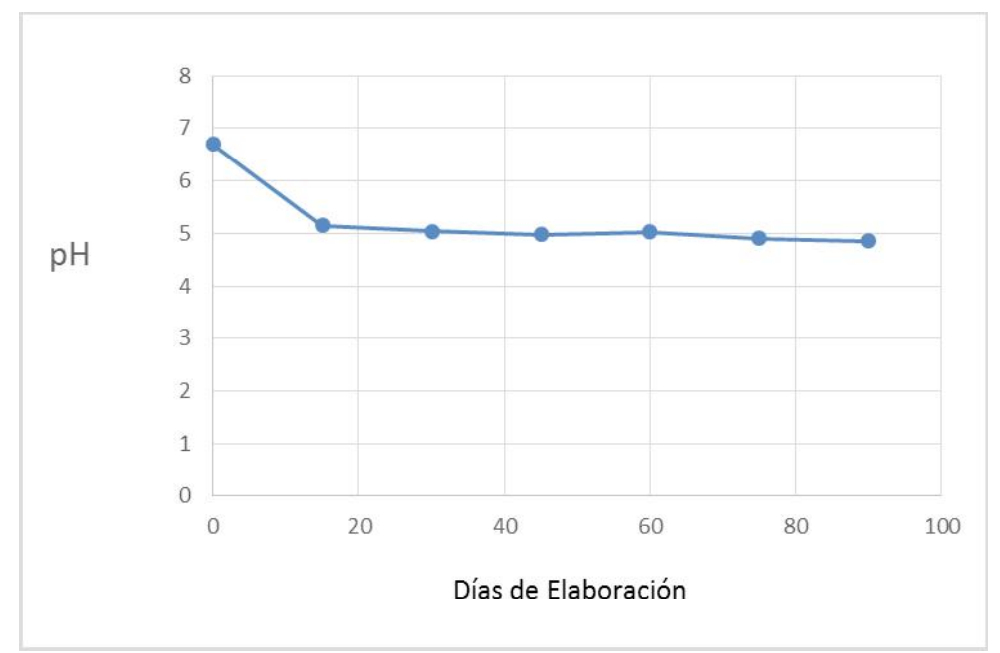

Figura 1. Comportamiento en el tiempo del pH en el producto FES-papa.

En estudios de Fes, en diversos productos como el Sacchaboniato y la pulpa del café $(12,13,14)$, se recalca que el $\mathrm{pH}$ es un indicador estrechamente correlacionado con la dosis de urea, la concentración de amoníaco y, en menor o mayor grado, con los AGVt (15).Al adicionar diferentes porcentajes de urea a las FES de caña de azúcar, se demostró que el amoníaco y los AGVt estuvieron altamente correlacionados con el $\mathrm{pH}$ del Sacchamaíz, Sacchasorgo y Sacchacítrico (13).

Lo anterior nos permite inferir que se dieron las condiciones adecuadas para la fermentación del alimento. Como control se realizaron tres muestreos a los 0, 30 y 90 días, muestras que se co- rrieron bajo los protocolos ya establecidos para el análisis químico.

El comportamiento de la MS se inicia con un $80,2 \%$; el comportamiento es descendente, como se observa en la Fig.2, siendo más significativo (15 puntos porcentuales, aprox.) de los 30 días de muestreo frente a los 90 posteriores, pasando de 76,1 a $61,7 \%$.Se indica que la acción microbiana provoca una reducción de MS en el tiempo durante procesos FES producto de la utilización de azúcares (sacarosa, glucosa, fructosa) y almidón en sus procesos metabólicos, generando agua, $\mathrm{CO} 2$ y AGV (16), al evaluar procesos FES luego de 48 horas de fermentación.

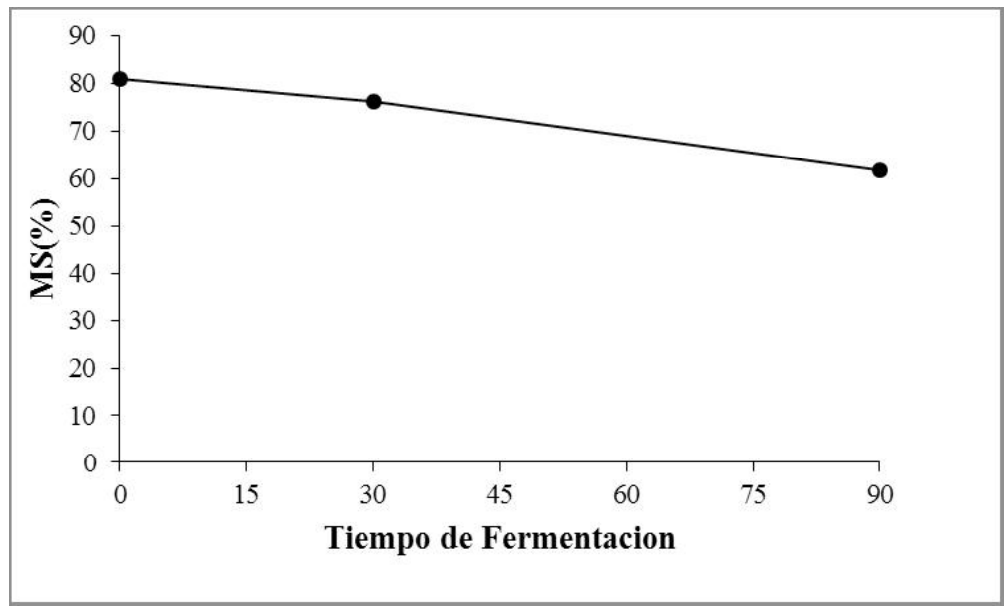

Figura 2. Comportamiento de la MSa los 0, 30 y 90 días de fermentación. 
La disminución de la MS también se puede deber a la hidrólisis de la urea y, posiblemente en menor escala, a la desaminación de péptidos y aminoácidos con la producción de amoníaco que se pudiera volatilizar en dependencia del $\mathrm{pH}$ final del proceso, por los microorganismos presentes en el ecosistemas durante sus procesos metabólicos para síntesis celular, oxidándolos a ácidos grasos (que pudieran ser usados por levaduras y bacterias), $\mathrm{CO} 2$ y $\mathrm{H} 2 \mathrm{O}$ (17). Parte del agua producida durante la oxidación de las moléculas pudiera evaporarse por el calor metabólico que se genera durante el proceso de FES $(11,18)$.

En cuanto a la proteína (Fig. 3), encontramos un leve descenso a los 30 días frente a la inicial, con una gran recuperación a los 90 días $(21 \%)$, llegando casi a la proteína original. La proporción de la $\mathrm{PC} / \mathrm{PV}$ se mantiene para los muestreos sobre el $68 \%$, incluso a los 30 días, cuando se deprime.
Podemos pensar que este tipo de alimento pudiera competir con alimentos comerciales; además, se demostró el potencial que tienen los procesos de FES en la producción de alimentos de mayor valor nutritivo para los animales, como los elaborados a partir de materiales fibrosos con bajo contenido de proteína, y disponibles local o regionalmente, como es el caso de la caña de azúcar (19).

Otros trabajos en FES han obtenido resultados similares en niveles de proteína; en un ensayo empleando bagacillo de retorno, con $24 \mathrm{~h}$ de fermentación y con inclusión de $20 \%$ de pulido de arroz, se alcanzaron valores promedio de 21,1 a $27,1 \%$ de PB y de 9,9 a $11,9 \%$ de PV, con temperaturas de incubación de 38,5 a $45,8{ }^{\circ} \mathrm{C}$ (20). También en la FES de garbanzo se obtuvo un incremento de proteína cruda de 19,6 a 23,2\%, y de proteína verdadera 19,9 a $23,4 \%$ en desechos de garbanzo (21).

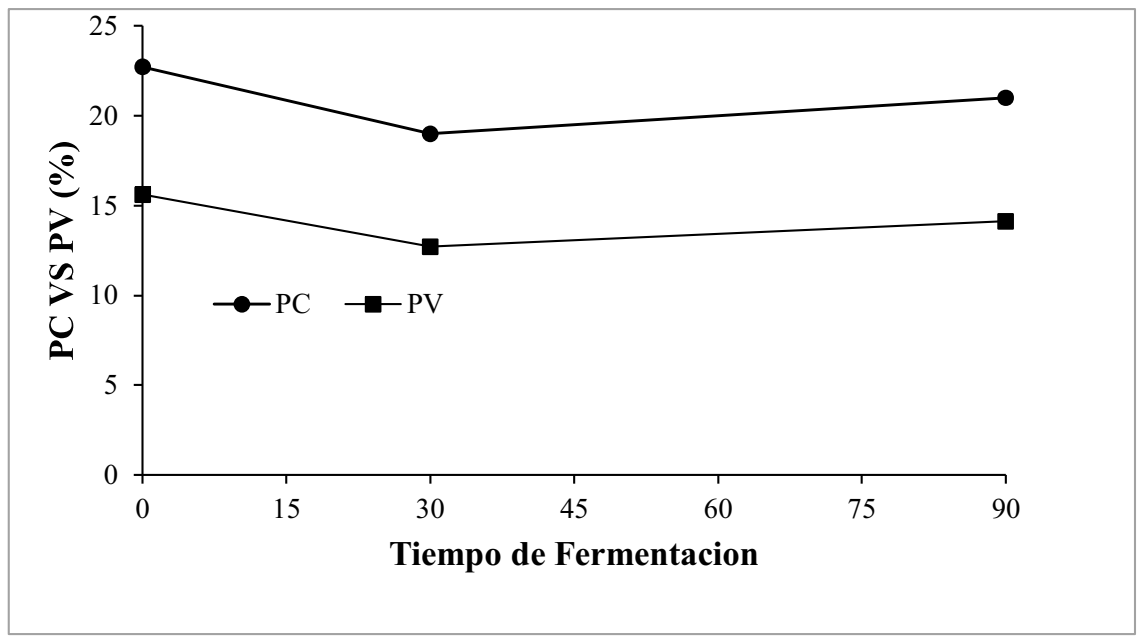

Figura 3. Comportamiento de la proteína en los diferentes tiempos de fermentación.

Finalmente, cabe destacar que en la papa, aproximadamente, el $50 \%$ de la PC corresponde a compuestos nitrogenados no proteicos, uno de los cuales es la solanidina, alcaloide que puede estar presente libre o combinado en forma de glicoalcaloides denominados chaconina y solanina, ambos tóxicos para los animales (22). Se infiere que este inconveniente también se ve contrarrestado al someter los desechos de papa a Fermentación en
Estado Sólido, pues en este caso la mayoría de la proteína es de origen microbiano y no directamente del alimento.

Finalmente, el comportamiento de la fibra en el alimento (Fig. 4); se observa que en promedio tenemos un descenso para la fibra de aproximadamente 20 puntos porcentuales (FDN y FDA), lo cual mejora sensiblemente la digestibilidad del alimento. 


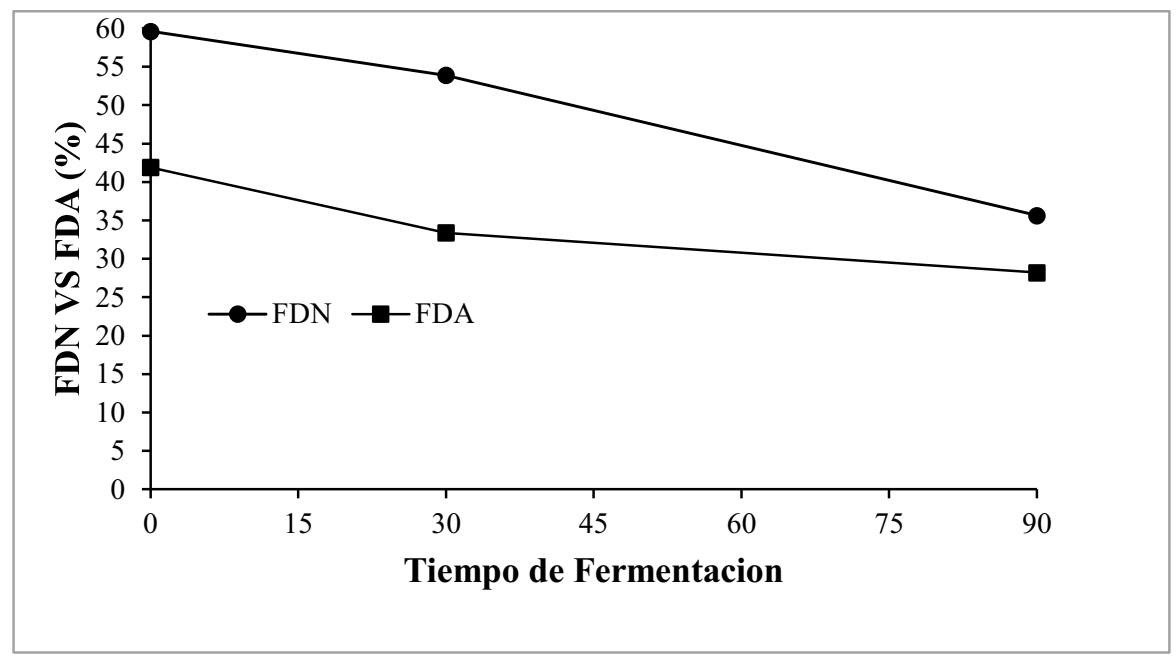

Figura 4. Comportamiento de la fibra a los 0, 30 y 90 días de fermentación.

El contenido de fibra cruda en la papa cruda varía normalmente entre $3 \%$ y $4 \%$, lo cual implica la necesidad de combinar este alimento con otros ricos en este elemento, a fin de producir un mejor aprovechamiento específicamente en los rumiantes (22); adicionalmente, un alto porcentaje de papas en la ración puede ocasionar problemas digestivos por un efecto laxante y de meteorismo.
Se observan datos similares en trabajos de ensilajes de papa con kikuyo (23), con una FDN de 56,2 y 29,6 de FDA, coincidente con el presente estudio en la inclusión de alfalfa.

Por otra parte, en el presente trabajo, con el objeto de facilitar el proceso fermentativo, se adicionó un inóculo (preparado microbiano) que presenta las siguientes características en el momento de la adición al producto antes de ser fermentado (Tabla II).

Tabla II. Resultado del análisis microbiológico del preparado microbiano

\begin{tabular}{|c|c|}
\hline Análisis microbiológico & Resultado \\
\hline Aerobios mesófilos (UFC/g) & $50 \times 10^{6}$ \\
\hline Coliformestotales (NMP) & 23 \\
\hline Coliformesfecales (NMP) & $<10$ \\
\hline Esporas Clostridum Sulfito Reductor (UFC/g) & Mohos: 20 \\
\hline Mohos y levaduras (UFC/g) & Levaduras: $<11 \times 10^{3}$ \\
\hline Salmonella & Ausente \\
\hline Bacterias acidolácticas & $99 \times 10^{6}$ \\
\hline
\end{tabular}


Por su parte, el incremento hallado en los porcentajes de proteína puede atribuirse a que se mantuvo un $\mathrm{pH}$ dentro de un rango adecuado para el crecimiento de los microorganismos (ver Fig. 1); estos, a su vez, hacen uso de la energía disponible en forma de carbohidratos solubles que la papa proporciona, utilizada para la retención de amoniaco y posterior conversión de NNP en nitrógeno proteico a través de procesos físico-biológicos $(24,18)$. Elías et al.(4) indican que la eficiencia de conversión de los carbohidratos solubles a proteína puede llegar a valores de $61 \%$, debido al desarrollo de la microbiota que se establece en el sistema cuando este le proporciona las condiciones adecuadas para su crecimiento. También, Ramos et al.(18) reportan que empleando inoculación con microorganismos benéficos Vitafert ${ }^{\circledR}$ en Sacchasorgo y Sacchapulido se observó una mayor retención de amoníaco, debido al menor $\mathrm{pH}$, lo cual incrementó el contenido de PC de estos alimentos. Además, el investigador afirma que a pesar de que la inoculación con el Vitafert ${ }^{\circledR}$ no tuvo el incremento en PV esperado, es importante usar este producto, ya que el $\mathrm{pH}$ que se obtiene al final de la FES nos permitiría conservar húmedo el producto almacenado, lo que evitaría que otros microorganismos no deseables se establezcan. Adicionalmente, de acuerdo con los resultados de Rodríguez (17), sería importante buscar estrategias que permitan que cuando se use el Vitafert ${ }^{\circledR}$ como inóculo el pH no descienda bruscamente en las primeras horas y no afecte los microorganismos que se desarrollan en estos procesos, como se ha mencionado anteriormente, efecto que no se presentó en nuestro estudio con el inóculo elaborado, ya que los valores del $\mathrm{pH}$, si bien tendieron a disminuir, no lo hicieron de manera abrupta, asumiendo el favorecimiento en el crecimiento de proteína de origen microbiana en el alimento.

Como se referencia en la metodología, con el objeto de verificar el comportamiento microbiológico del alimento se realizó un muestreo (30 días) que se sometió a un análisis microbiológico; es de anotar que dicha decisión de realizar un muestreo del producto final de la Fes-papa tenía como objeto analizar la inocuidad del producto, y así poder realizar una prueba biológica de él con animales. El resultado del análisis se presenta en la Tabla III.

Tabla III. Resultado del análisis microbiológico de Fes-papa

\begin{tabular}{|c|c|}
\hline Análisis microbiológico & Resultado \\
\hline Aerobios mesófilos (UFC/g) & $14 \times 10^{6}$ \\
\hline Coliformestotales (NMP) & 3,6 \\
\hline Coliformesfecales (NMP) & $<3$ \\
\hline Esporas Clostridum Sulfito Reductor (UFC/g) & $<10$ \\
\hline Mohos y levaduras (UFC/g) & Mohos: 40 \\
& Levaduras: $<10^{3}$ \\
\hline Salmonella & Ausente \\
\hline BacteriasAcidolácticas (UFC/g) & $50 \times 10^{6}$ \\
\hline
\end{tabular}

Es importante anotar que no existe una norma de calidad de comparación para este tipo de productos fermentados para uso en la alimentación animal, sin embargo, los resultados nos permiten inferir que es un producto inocuo que puede ser 
utilizado sin riesgo biológico para el consumo animal.

\section{Conclusiones}

El producto Fes-papa presenta modificaciones de relevancia en indicadores fermentativos y en el contenido de materia seca, proteínas y su componente de fibra; el $\mathrm{pH}$ desciende y se estabiliza en corto tiempo, lo que se relaciona con la posibilidad de conservación del alimento; se infiere que es un producto inocuo que se pudiera emplear en la alimentación animal.

\section{Referencias}

(1) Moreno J. Calidad de la papa para usos industriales, Corpoica, 2010. Recuperado de: http://www.todopapa.com.ar/pdf/calidadpapaparausosindustriales.pdf.

(2) Danelón J. Comprendiendo a los carbohidratos.2001. Recuperado de: http://www.produccion-animal.com.ar/informacion tecnica/ manejo_del_alimento/56-comprendiendo_a_ los_carbohidratos.pdf.

(3) FAO. Estudio FAO investigación y tecnología 8. Biotecnología agrícola para países en desarrollo. Resultado de un foro electrónico. Roma. 2003. Recuperado de: http://www.fao. org/documentes/show_cdr.asp?url file =/DOCREP/004/Y2729S/y2729s00.htm.

(4) Elías A, Lezcano O, Lezcano P, Cordero J, Quintana L. Reseña descriptiva sobre el desarrollo de una tecnología de enriquecimiento proteínico en la caña de azúcar mediante fermentación solida (Saccharina). Rev. Cubana Cienc. Agríc., 1990. 24 (1):3-12.

(5) Elías A, Lezcano O, Herrera F. Algunos indicadores bromatológicos y productos finales de la fermentación para la obtención de cuatro tipos de Saccharina inoculados con Vitafert. Rev. Cubana Cienc. Agric., 2001. 35(2): 153158.
(6) Municipio de Oicatá (Boyacá), Oficina de Planeación. Plan de Ordenamiento Territorial, POT.2014.

(7) Conway E.J. Microdiffusion analysis and volumetric error. 4th ed. Crosby Lockwood and Sons, Ltd. London, 1957.

(8) AOAC, Official Methods of Analysis, 17th. Ed. Assoc. Off, Agric. Anal.Chem. Arlington, Virginia. 2000, p. 580.

(9) Meir H. Labor pralecte kuretierernahrung und juttermitlehunde fur tiere produzion Verlag. D.D.R.1986.

(10) Van Soest P. J., Robertson J. B. \& Lewis B. A. Methods for dietary fiber, neutral detergent fiber and nonstarch polysaccharides in relation to animal nutrition. J. Dairy Sci., 1991; 74:3583.

(11) Pandey A., Soccol C.R., Rodríguez-León J.A. y Nigam P. Solid-state fermentation in biotechnology. Fundamentals and applications. Asiatech Publishers, Inc. New Delhi.2001. 221 p.

(12) Aksu T., Baytok E., Bolat D. Effects of a bacterial inoculant on corn silage fermentation and nutrient digestibility. Small Rum. Res. 55: 249-252. DOI: 10.1016/j.smallrumres.2003.12.012. 2004.

(13) Cárdenas JR., Aranda EM., Hernández D., Lagunes L.C., Ramos JA., \& Salgado S. Obtención de un alimento fermentado en estado sólido a partir del bagacillo de retorno, pulido de arroz e inóculos. Su utilización en la alimentación animal. Rev. Cubana Cien. Agric., 42(2):173-176.

(14) Rodríguez R. H. E. Producción y evaluación de alimentos fermentados a partir de bagazo y desecho de manzana y su efecto sobre el desarrollo ruminal y parámetros sanguíneos. [Tesis Doctoral]. Universidad Autónoma de Chihuahua.2009. 
(15) Echeverría J, López P, Mato S. Alternativas para la alimentación animal utilizando fermentación en estado sólido. Revista Avanzada Científica [en línea]; 6(1). Recuperado de: http://avanzada.idict.cu/avanzada/article/ view/62/72.2003.

(16) Rodríguez Z, Boucourt R, Elías A, Madera M. Dinámica de fermentación de mezclas de caña (Saccharumofficinarum) y boniato (Ipomea batata). Rev. Cubana Cienc. Agric., 2001. 35 (2):147-151.

(17) Rodríguez B.Y. Obtención de un alimento energético proteico a través de la FES de la caña de azúcar y el tubérculo de yuca [Tesis de Maestría]. Universidad Agraria de la Habana. Instituto de Ciencia Animal. Habana, Cuba. 2005.

(18) Ramos J., Elías A., Herrera F., Aranda E.\& Mendoza G. Procesos para la producción de un alimento energético-proteico para animales. Efecto de niveles de miel final en la fermentación en estado sólido del Saccha-sorgo y Saccha-pulido, Rev. Cubana Cien. Agric.2007, Tomo 41, N. ${ }^{\circ} 2$.

(19) Ramos J., Elías A., \& Herrera F. Procesos para la producción de un alimento energético-proteico para animales. Efecto de cuatro fuentes energéticas en la fermentación en estado sólido (FES) de la caña de azúcar. Rev. Cubana Cien. Agric.2006, Tomo 40, N. ${ }^{\circ} 1$.
(20) Elías A. \& Lezcano O. Inclusión de niveles de harina de soya desgrasada y sin desgrasar en la fermentación de la caña de azúcar en estado sólido. Sacchasoya. Rev. Cubana Cien. Agric., 2000.34:143.

(21) Gómez Garza RM, Reyes Moreno C, Romero Urias CA, Milán Carrillo J. Composición química y calidad nutritiva de garbanzo (Cicerarietinum L.) fresco y endurecido después de la fermentación en estado sólido (FES). Food Science and Technology International (Española), 2000, 6(3):251-258.

(22) Siebald E, Goic L, Matzner M. Alimentación de rumiantes con papa de desecho. Boletín Técnico N. ${ }^{\circ} 88,2002$. Instituto de Investigaciones Agropecuarias - Centro Regional de Investigaciones Remehue. Recuperado de: http://www.produccion-animal.com.ar/informacion_tecnica/suplementacion/99-papa.pdf.

(23) Ruiz J. Evaluación de la producción y calidad de la leche en vacas Holstein de primer parto suplementadas con ensilaje de papa, [Tesis Pregrado]. Universidad de la Salle, Bogotá, Colombia.2006.

(24) Valiño E., Elías A., Álvarez E., Quintana M. \& Montes de Oca N. Composición de especies de bacterias aisladas del proceso de obtención de la Saccharina. II. Bacterias gram positivas. Rev. Cubana Cienc. Agríc., 1994; 28:75. 